\title{
Shell shape of the land snail Cornu aspersum in North Africa: unexpected evidence of a phylogeographical splitting
}

\author{
L Madec ${ }^{1,2}$, A Bellido ${ }^{3}$ and A Guiller ${ }^{4}$ \\ 'Université de Rennes 1, UMR CNRS 6553, Equipe 'Evolution des populations et des espèces', France; ${ }^{2}$ Service de Zoologie et \\ d'Ecophysiologie, Bât. 14, Campus de Beaulieu, avenue du Gal Leclerc, 34042 Rennes cedex, France; 'Service d'Ecologie du sol et de \\ Biologie des populations, Station biologique de Paimpont, 35380 Paimpont, France; ${ }^{4}$ Laboratoire de Parasitologie Pharmaceutique, \\ Faculté des Sciences Pharmaceutiques et Biologiques, 35043 Rennes cedex, France
}

\begin{abstract}
Anatomical and molecular characters used to differentiate populations of the land snail Cornu aspersum (Helix aspersa) exhibit, in the western Mediterranean, definite and concordant patterns of correlation with geography. Scenarios involving Pliocene geological changes and postglacial expansion during the Pleistocene were proposed in previous studies to account for the establishment of this geographical structure. In the present work, we have performed a spatial analysis of variation in shell morphometrics, after the partitioning of the overall variation into size and shape components by means of a principal component-based approach (Cadima and Jolliffe, 1996). In order to know if the same historical events have also structured shell variation, the analysis includes all the populations from North Africa which were investigated for anatomical and molecular surveys. Contrary to shell size, which shows a significant
\end{abstract}

spatial heterogeneity essentially related to environmental pressures, variation in shell shape components splits the populations according to a geographical pattern reflective of hypotheses suggested for molecular markers and genital anatomy. This implies that the selective forces often invoked to explain spatial changes in shell shape are not the deciding factors in the present case. Moreover, within each of the two geographical clusters defined, Mantel correlograms show that the similarity between populations declines according to an isolation by distance model. Because of the different allometric relationships between shell size and genitalia measurements in Western and Eastern entities of North Africa, mechanical constraints, possibly leading to a precopulatory isolation in the contact zone, are involved. Heredity (2003) 91, 224-231. doi:10.1038/sj.hdy.6800301

Keywords: $\quad$ spatial structure; multivariate morphometrics; Cornu aspersum; western mediterranean; plio-pleistocene events

\section{Introduction}

In land snails, shells often provide relevant morphometric data used in taxonomy and phylogenetic inference as well as in population biology. Shell morphology, which preserves the ontogenic record of growth, is now the principal subject of a subfield of morphometrics, namely theoretical morphology, which has led, since the initial mathematical modelling of Raup (1966), to convincing studies on the formal and historical determinants of shell forms, as well as functional interpretations of their observed distributions in theoretical morphospaces (eg, Stone, 1996, 1999; Mc Ghee Jr, 1999; Samadi et al, 2000). The shape of molluscan shells has also been characterized, in more traditional approaches, by the use of simpler measurements, such as the ratio of width to height (for a review, see Goodfriend,1986), or by the plotting of these two measurements in order to create a 'size/shape space' (Cain, 1981; Cameron and Cook, 1989). Multivariate morphometrics have also been extensively used to separate size and

Correspondence: L Madec, Campus de Beaulieu, Avenue du Gal Leclerc, 35042 Rennes cedex, France. E-mail: luc.madec@univ-rennes1.fr Received 15 July 2002; accepted 28 February 2003 shape components of the shell but, following the major paper of Rohlf and Marcus (1993) on morphometric methodology, there is now a clear tendency to record sufficient data in order to allow the recreation of the structure being studied (Stone, 1998; Monteiro et al, 2000).

In North Africa, native populations of the Mediterranean land snail Cornu aspersum (Helix aspersa) show conspicuous shell variation, which has been the subject of extensive studies, leading to the recognition of several endemic forms (Germain, 1908; Taylor, 1913). However, the typological approach adopted by these authors to investigate the morphological variation provides no information about the shells multivariate geographical pattern, and ignores the nature of the differentiation between morphotypes. Another problem is that this methodology produces a description based on shell phenotypes alone. More recently, research has been carried out in the light of 'modern' population biology, which has included: (i) a comparative study of the geographical variation of potentially independent sets of data, that is allozymes, mtDNA and morphological and anatomical features, in order to assess the processes responsible for the current geographical distribution of Cornu aspersum on the Mediterranean and western 
European coastline (Madec, 1991a, b; Lazaridou-Dimitriadou et al, 1993; Madec and Guiller, 1994; Guiller et al, 1994, 2001), and (ii) the investigation, in artificial conditions, of the genetic component of variation in some conchologically distinct morphologies in relation to their life-history tactics (Madec and Daguzan, 1993; Madec et al, 1998). In this way, genital anatomy has already been used in a biogeographical context (Madec and Guiller, 1994), but distance matrices resulting from measurements of these soft body parts did not, in early studies, take consideration of (i) the distinction between size and shape effects, and (ii) recent developments elucidating the functional relationships between some parts of the distal genitalia (Koene and Chase, 1998; Van Osselaer and Tursch, 2000).

In this study, we focus on shell and genital features, without taking geometrical relationships among measurements into account. We do this, not because of logistical problems (see Johnston et al, 1991; Stone, 1998), but because our main aim is not to recover the overall form of a structure but to search for a geographical pattern in shape variation among samples, with individuals adjusted to a common size (see Rohlf, 1990). We use the technique proposed by Cadima and Jolliffe (1996), which results in the partitioning of the overall variation into size and shape components, but without the major drawbacks found with other principal component-based approaches that also produce an isometric vector (Somers, 1989; Bookstein, 1989; Yoccoz, 1993). Populations from Western Europe are excluded from the analyses because of their recent introduction by man and consequent loss of genetic variation. In fact, despite locally significant differences, this area is characterized by a high homogeneity in shell morphology and genital anatomy.

In a second step, we search for the spatial structure of the variation of shape components, by means of autocorrelation methods. The patterns obtained are then discussed in the light of those resulting from analyses based on allozymes and mtDNA sequences, variations which are commonly assumed to be selectively neutral.

\section{Materials and methods}

\section{Sample collection and measurements}

For this study of shell variation, we have retained a total of 577 snails from the 31 North African samples of Cornu aspersum previously studied for allozymic and mtDNA variation (Figure 1). Five shell measurements were taken either on the axial view (SH: height; SW: width; SD: maximum diameter) or on the apertural view (AL: aperture length from the point of adhesion of aperture to body whorl; AW: maximum aperture width) in order to describe quantitatively the size and shape. Only shells with a reflected lip were used because this indicates the cessation of growth, together with the maturity of the snail. These measurements mirrored general aspects of size and shape already used by earlier workers for their catalogues (see Taylor, 1913), which are essentially based on the ratio of width to height and the relative size and shape of the aperture. Moreover, breeding experiments have shown that a large part of the variation leading to the characterization of some morphotypes is genetically determined (eg the 'giant' form Helix aspersa maxima Taylor or the 'conical' form Helix aspersa conoidea Picard) but, within a given form, the variation in the trait itself is sometimes subject to a strong environmentally induced component (Madec and Guiller, 1993; Madec et al, 1998).

Nine measurements of the reproductive anatomy were carried out in each of 269 specimens according to the methods and nomenclature described in Madec and Guiller (1994). However, recent developments related to the functional morphology of the reproductive system in genus Helix have demonstrated sexual selection, based on the gametolytic power of bursa copulatrix and acting on covariation of some of its parts (Lace, 1992; Koene and Chase, 1998; Van Osselaer and Tursch, 2000). In order to take into account these potential correlations, the measurements used here were modified as follows: (1) FLAL + EPIL: length of flagellum and epiphallus (the spermatophore is formed in epiphallus and flagellum); (2) DIVL+BCL2: length of diverticulum and distal part of bursa copulatrix duct (the spermatophore is transferred into the bursa tract diverticulum and copulatory canal); (3) BCL1: length of proximal part of bursa copulatrix tract, (4) DSL: length of dart sac, (5) OVIL: length of vagina and genital atrium; (6) PENL: length of penis, (7) VDL: length of vas deferens.

\section{Statistical methods}

We used a traditional approach, that is multivariate statistics, in order to test for spatial structure in changes of shell shape among the samples. First, variables were $\log _{\mathrm{e}}$-transformed to obtain a linear functional relationship between them (A matrix) and then centred ( $\mathbf{X}$ matrix). Afterwards, we performed a covariance PCA

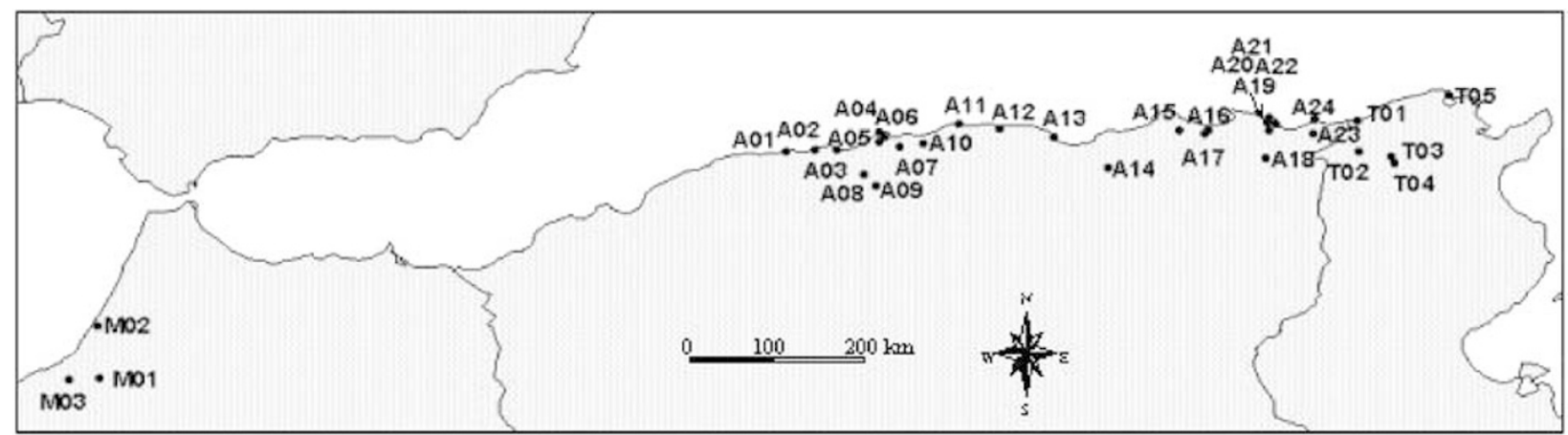

Figure 1 Location of the 31 sites sampled in North Africa. 
according to Cadima and Jolliffe (1996). This was an attempt to (i) give information about allometric relationships between log-transformed variables (PCA based on the covariance matrix, see Jolicoeur, 1963) and (ii) find shape components that are separate from size and from each other ( $\mathbf{Z}$ matrix, see below). This method, which retains both properties of original PCA, was used instead of the double-centring method (Somers, 1989, Yoccoz, 1993), for which the principal drawback is the loss of uncorrelatedness of PCA components with the isometric size component. Data analysis was conducted according to the following steps:

\section{1 'Shape-related' PCA:}

- Centring $\mathbf{A}$ by columns (variables) into $\mathbf{X}$.

- $\mathbf{Z}=\mathbf{X} \mathbf{Q}^{\prime}$ with $Q=I_{p}-\left(S a_{0}\right)\left(a_{0}^{\prime} S a_{0}\right)^{-1} a_{0}^{\prime}$.

$a_{0}^{\prime}=(1 / \sqrt{ } p)(1,1, \ldots 1)$ is the isometric size vector (matrix with a single row, transpose of the matrix $a_{0}$ ) for $p$ variables, $S$ is the covariance matrix of $A ; I_{\mathrm{p}}$ the identity matrix of order $p$ (note that in the case of double centring $\left.Q=I_{p}-a_{0} a_{0}^{\prime}\right)$

- Covariance matrix PCA of $\mathbf{Z}$.

- Graphical representation of the 31 populations according to their factorial scores.

\section{Clustering}

- Matrices of Euclidean distances (D) were calculated from the first three principal components ('shell' data) and from the first five components ('genitalia' data) of the corresponding PCA.

- A hierarchy was computed from D (shell data) according to a clustering analysis based on the 'inertia criterion', that is the minimization of the loss of interclass inertia at each step of the clustering (Ward, 1963).

- The interpretation of the hierarchy was based on a decomposition of the variance according to the contribution of each variable to the formation of each node. In such an analysis, a node level corresponds to the decrease in between-groups variance associated to the merging of two groups.

3 Mantel correlograms (Legendre and Fortin, 1989) were drawn by calculating Mantel $R$ values between the Euclidean distances (D) and binary matrices built for each class of geographical distances (see Results). Significance levels of individual $R$ values were tested against the null hypothesis of no spatial arrangement by a resampling procedure (1000 permutations). The overall significance of the entire correlograms was assessed using the Bonferroni technique (Oden, 1984).

\section{Software availability}

All calculations and graphs were made with ADE-4 (Thioulouse et al, 1997). The package can be obtained freely by anonymous FTP to pbil.univ-lyon1.fr, in the /pub/mac/ADE/ADE4 directory. A WWW documentation and downloading page is available at: http://pbil. univ-lyon1.fr/ADE-4.html, which also provides access to updates and user support through the ADEList mailing list.

\section{Results}

Analysis of shell variables yielded three principal components accounting in total for $98 \%$ of the total variance. Major contributions to the variance of the principal plane included $\mathrm{SH}$ vs SW and AW (Figure 2). The third component essentially distinguished between long vs wide apertures (Table 1). These oppositions between variables are related to a clear typology of populations depending on their eastern (conical shell) or western (larger aperture) origin (Figure 3). However, three samples, namely A09, A19 and M02, did not cluster with others of similar geographical origin, as is clearly shown in the dendrogram based on their factorial scores (Figure 4). The misclassification of the samples A19 and

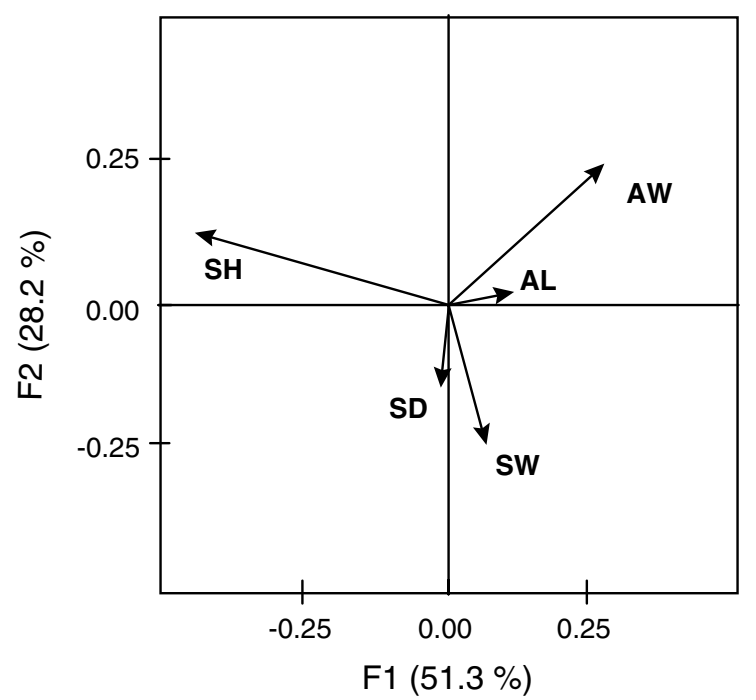

Figure 2 Projection of the morphometric variables on the principal plane of the size-constrained PCA on the shell data set.

Table 1 Size-constrained PCA performed on the shell data set

\begin{tabular}{|c|c|c|c|c|c|c|c|c|c|}
\hline & $F 1$ & $F 2$ & F3 & Ctr1 & Ctr2 & Ctr3 & Cor1 & Cor 2 & Cor3 \\
\hline Sw & 0.0066 & -0.0244 & -0.0085 & 0.0154 & 0.3828 & 0.0780 & 0.0562 & 0.7680 & 0.0935 \\
\hline Sh & -0.0438 & 0.0124 & -0.0018 & 0.6785 & 0.0983 & 0.0034 & 0.9230 & 0.0736 & 0.0015 \\
\hline Sd & -0.0013 & -0.0144 & -0.0039 & 0.0006 & 0.1336 & 0.0163 & 0.0050 & 0.5895 & 0.0429 \\
\hline $\mathrm{Al}$ & 0.0115 & 0.0021 & 0.0263 & 0.0466 & 0.0027 & 0.7441 & 0.1588 & 0.0051 & 0.8346 \\
\hline $\mathrm{Aw}$ & 0.0270 & 0.0244 & -0.0121 & 0.2588 & 0.3826 & 0.1583 & 0.4963 & 0.4038 & 0.0999 \\
\hline
\end{tabular}

For each variable, zth axis coordinates $(F z)$, contributions $(C T R z)$ to the inertia of $z$ factor, and correlations $(C O R z)$ with $z$-factor are given. COR represents $\cos ^{2}$ of the angle between a variable vector and factorial axes. 


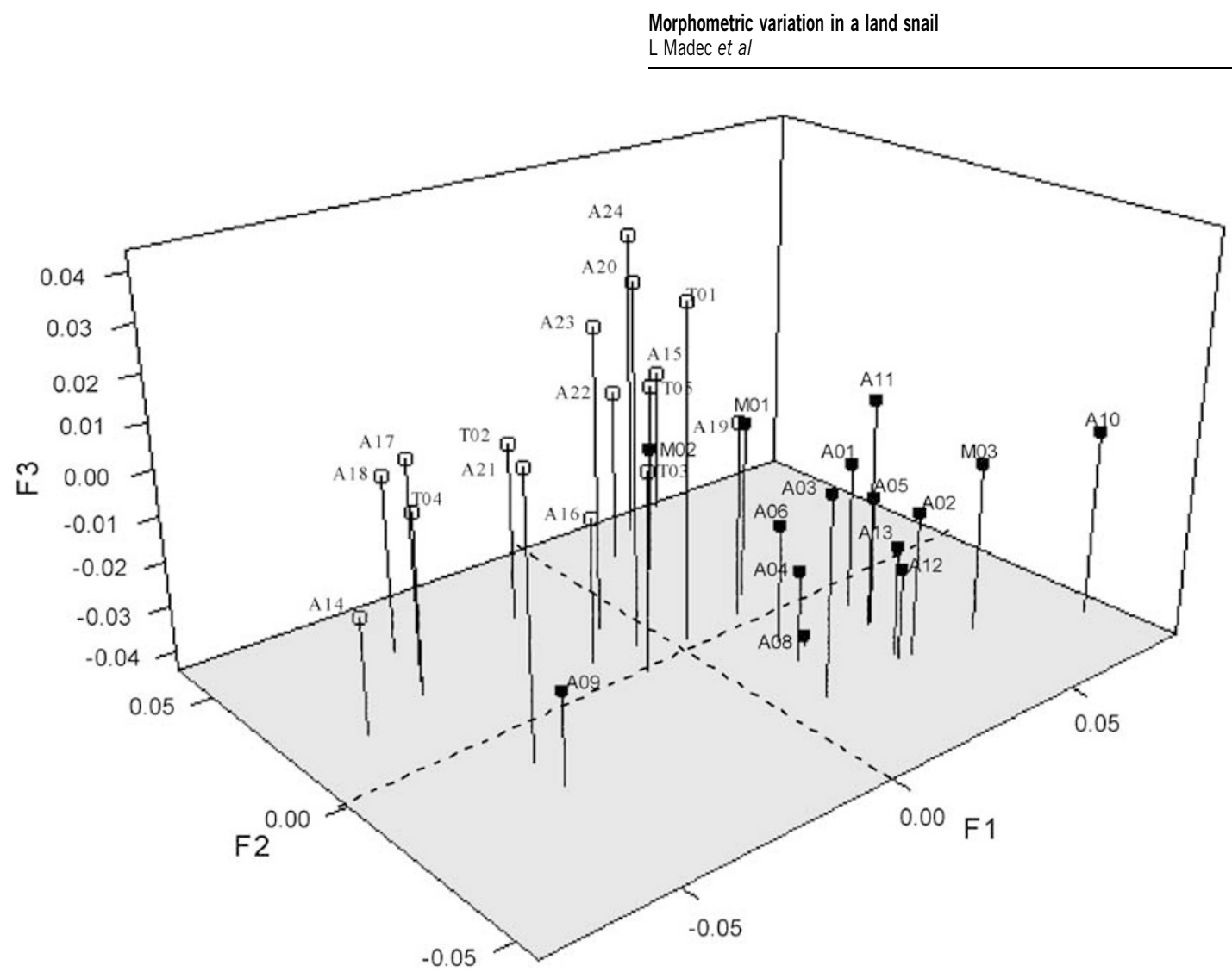

Figure 3 Size-constrained PCA performed on the shell data set. Populations are represented in a three-dimensional factorial space. Coordinates are obtained by computing intrapopulation averages as supplementary rows. Eastern and Western populations are distinguished on the graph with open squares and filled squares respectively.

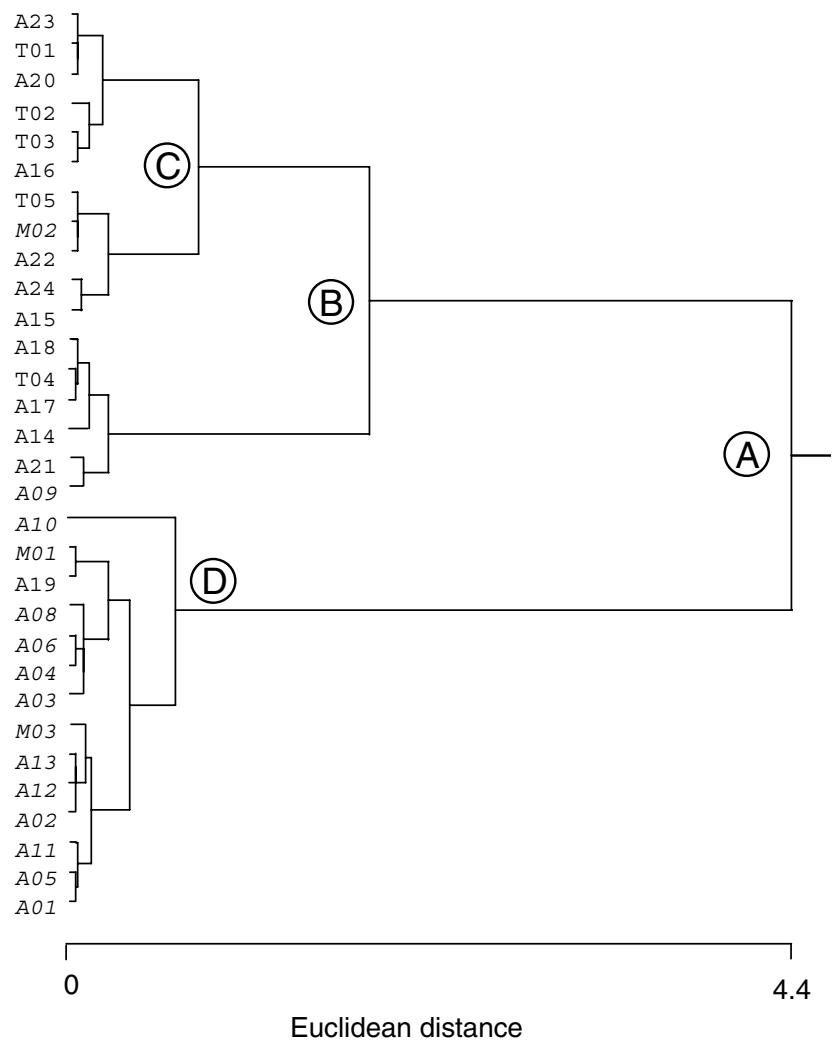

Figure 4 Hierarchy performed using Euclidean distances computed from the first three factors of the size-constrained PCA performed on the shell data set. The clustering algorithm is based on the Ward method (A B C D: nodes of higher level).
M02 could be attributable to the limits of the present analysis, that is (i) the small sample size for M02 (10 individuals) and the bad representation of its centre of gravity by axis 1 (correlation with the 1 st factor $=0.208$ ), and (ii) the projection of A19 very close to M01 but not to the western group (Figure 3). The examination of individual scores (coordinates and contributions) showed that the unexpected position of sample A09 (29 individuals) cannot be explained by such analysis bias.

Moreover, the contributions of the morphometric variables to the nodes of the hierarchy indicated that the large distance between A10 and the overall centre of gravity was related to the globular form of the shells in this sample (node D-SH: 76\%), and that the splitting of the eastern cluster into three subgroups (nodes B and C) was essentially based on the variance of AW (data not shown).

Factorial coordinates were also converted to Euclidean distances between populations, which were used in the construction of Mantel correlograms (Figure 5). Results from the previous analysis (Figure 5 (A-II)) were compared with data resulting from a PCA without size constraint, which was also performed on the shell measurements (A-I). This latter case showed slight fluctuations on the correlogram, of $r z$ close to 0 (X-axis), that is no spatial structure. However, the analysis after removing size effects showed a progressive decrease of $r z$ until the $375 \mathrm{~km}$ distance class, that is a decline of morphometric similarity with increasing geographical distance within each geographical entity (cf. scale in Figure 1). In contrast, correlograms based on population scores after PCA for the genitalia measurements (size constrained (B-II) or not (B-I) showed, in each case, a 
(A-I)

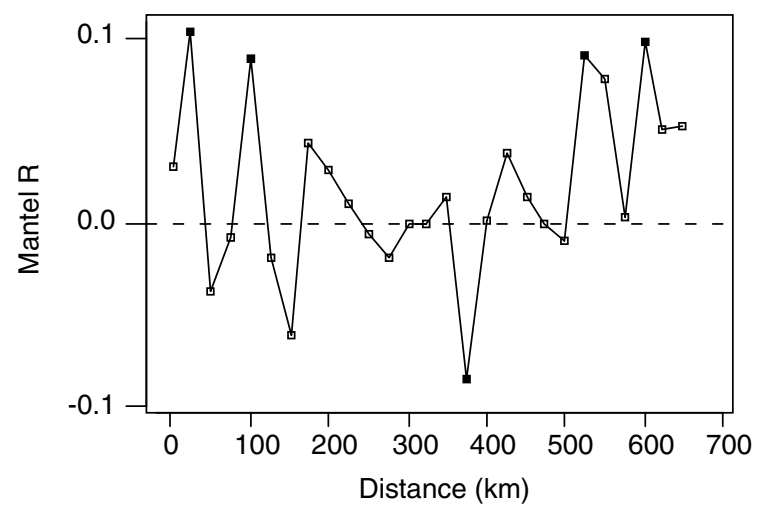

(B-I)

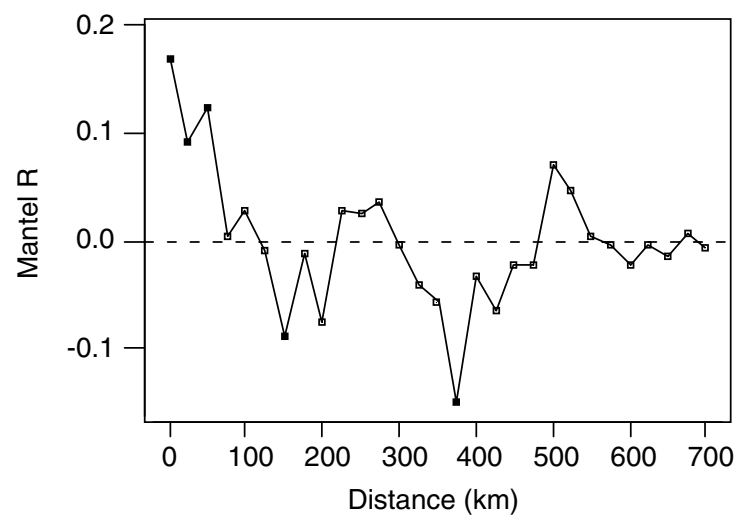

(A-II)

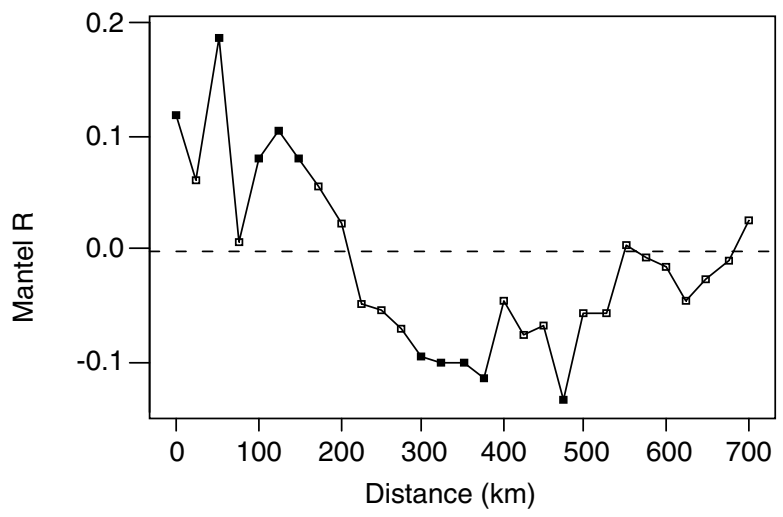

(B-II)

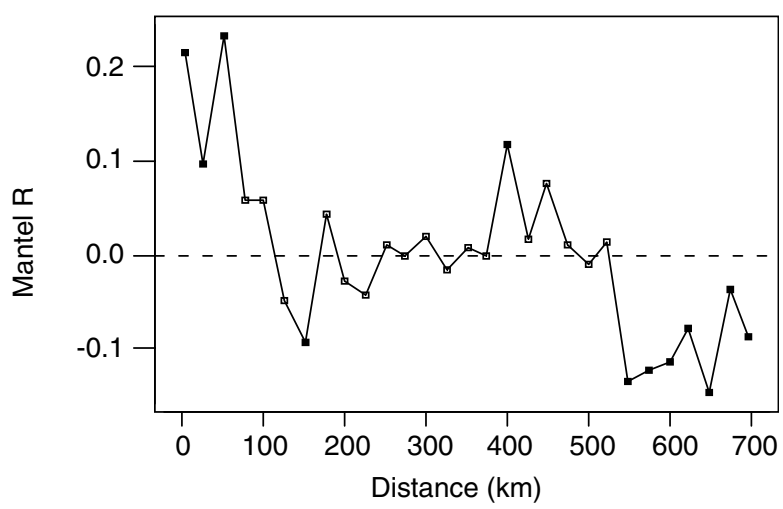

Figure 5 Mantel correlogram (distance class: $25 \mathrm{~km}$ ) performed on Euclidean distances between 31 populations, after covariance PCA on logtransformed data. A: Shell data, B: genitalia; I: unconstrained PCA, II: size-constrained PCA. Filled squares indicate significant correlations.

quite different spatial pattern involving, (i) from 0 to $150 \mathrm{~km}$, a smooth decline of $r z$ from significant positive values to negative ones, (ii) from 150 to $675 \mathrm{~km}$, fluctuations of $r z$ around 0 for B-I, but a strong decrease of $r z$ for the most distant pairs of sites $(550-675 \mathrm{~km})$ when size effects were removed (B-II).

However, one also notes the zero value of $r z$ for the $75 \mathrm{~km}$ class in A-II, which disrupts the pattern of a progressive decline of $r z$. The examination of all pairs of populations involved in this class showed that this unexpected result was essentially based on few populations located near the boundary of western and eastern entities, namely A9, A10, A13, A14 and A15. These populations are characterized by 'morphometric' distances $\left(d_{\mathrm{m}}\right)$ that are well above the average of all the pairs included in this geographic distance class $\left(0.103<d_{\mathrm{m}}<\right.$ 0.124 and $\left.d_{\mathrm{m}}=0.060\right)$. As an illustrative example, projection on axis 1 of the size-constrained PCA of A9 and A10, only separated by $78 \mathrm{~km}$, produced one of the highest morphometric distances (see Figure 3).

\section{Discussion}

During the last decade, increasing interest has been devoted to phylogeographical studies of C. aspersum, largely because of the contrast in genetic variability between western European populations, which are poorly diversified apart from some Mediterranean areas, and populations from North Africa, which are spatially well-structured on the basis of a high degree of diversity in allozymes and in mtDNA sequences (Guiller et al, 1994; Madec et al, 1996; Guiller et al, 2001). Within North Africa, the molecular variation shows a clear West $v$ s East cleavage with the populations from Lesser Kabylia at the intersection. Using autocorrelation statistics, scenarios related to vicariant events are illustrated by highly significant positive values for neighbouring populations $(0-75 \mathrm{~km})$ and random or negative ones for distant populations $(>400 \mathrm{~km}$ ), because of clusters well defined by very different allelic frequencies and/or private allozyme alleles (Figure 6). However, the progressive decline from significantly positive values to significantly negative ones over the range of distance from 0 to approximately $400 \mathrm{~km}$ is consistent with another spatial pattern, often confounded by vicariance (see Sokal et al, 1997; Bossart and Prowell, 1998), specifically, a neutral model of isolation by distance within each region. Thus, Pliocene geological changes (vicariance) and postglacial expansion during the Pleistocene, especially after the last pleniglacial periods that would create isolation by distance, may have both played leading roles in the establishment of the present spatial structure of genetic variation in this part of the distribution area (see Giusti and Manganelli, 1984; Guiller et al, 1994; Guiller et al, 2001). Here in the western Mediterranean, the effects of vicariance and isolation by distance will not be blurred by recent processes of human activity.

Previous results related to the variation of distal genitalia over the whole range of this species are largely 


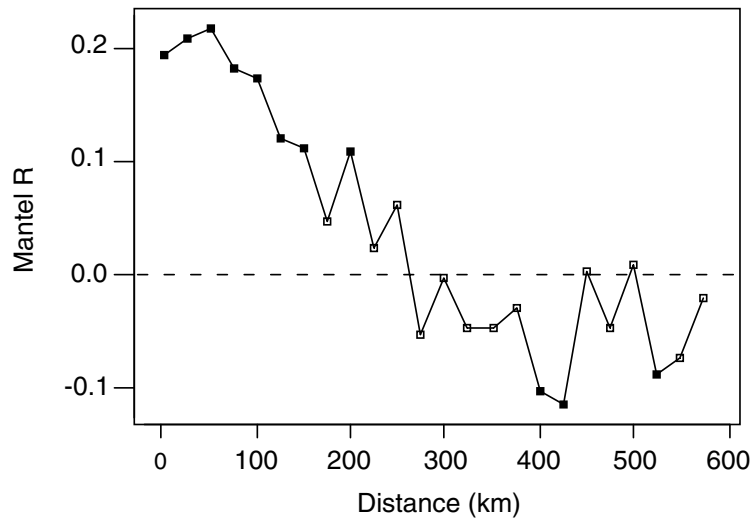

Figure 6 Mantel correlogram (distance class: $25 \mathrm{~km}$ ) performed on Nei (1972) genetic distances between populations from North Africa with 13 enzymatic loci (77 alleles: allelic frequencies available in Guiller et al, 1994).

concordant with this spatial pattern and also confirm the geographical isolation of the eastern part of North Africa (Madec and Guiller, 1994). In the present work, a subset of these data was analysed using a different statistical methodology, and in a way allowing the consideration of functional relationships between male and female parts. Nevertheless, the same main clusters of populations are produced. However, the correlograms provide additional information, that is they show a progressive decrease in morphometric similarity among populations (isolation by distance) within a $0-150 \mathrm{~km}$ range of geographic distances.

Conchological variability, expressed previously by shell size-related measurements, failed to show such a geographical cleavage (see Figure 4, A-I): size heterogeneity was not geographically structured, despite a high degree of interpopulation variation, of which a large part seems to be environmentally determined (Madec and Guiller, 1993; Dupont-Nivet et al, 1997a, b). However, a marked shell size differentiation seen in restricted areas has been used in the past as the basis of the assignment of a 'varietal' name to several forms, the best known being the giant Algerian subspecies H.a. maxima Taylor. H.a. maxima has been more recently redefined by numerous heritable traits identified in breeding populations, but we have never found on the field populations showing all of the maxima features. With the exception of minor discrepancies (see Guiller et al (2001) for an explanation relevant to the Moroccan populations), the variation in shell shape components splits the populations here according to a geographical pattern reflective of the historical hypotheses that have been suggested for molecular markers and genitalia. If all the four data sets can be considered as being independent, these qualitatively similar spatial distributions of variation argue that shell shape components, as used here, are not significantly influenced by environmental pressures. This is a result that has seldom been suggested for other wellstudied snails, for shell shape as defined by a ratio shell height/shell diameter (eg intertidal snails: Boulding and Hay 1993; Parsons, 1997; Johnson and Black, 2000; land snails: Goodfriend, 1986; Cameron and Cook, 1989; but see Welter-Schultes, 2000) or by shell aperture (Gittenberger, 1996). In contrast, differences in shell size between populations belonging to the same form are often influenced by local conditions and illustrate this trait's high degree of phenotypic plasticity, this plasticity frequently being involved in life-history tactics, essentially through the trade-off between age and size at maturity (Madec and Daguzan, 1993; Madec et al, 2000). In laboratory conditions, the evolution of experimental populations differing in shell size (SD) and shape (SH/ SD) demonstrated that, (i) giant size is maintained through several generations only in maxima, and (ii) the 'conical' trait (height approximately equal to the diameter), often observed in populations from eastern Maghreb, is retained in the F1 generation even though giant size relative to the same natural populations is lost. More generally, the $\mathrm{SH} / \mathrm{SD}$ ratio is constant through generations reared under artificial conditions, whatever the SH/SD value of the first generation may be. These results were based on experiments involving, among others, the natural populations of Djemila (A14) (Madec and Guiller, 1993), of Djemila and of El Bouni (A22) (Dupont-Nivet et al, 1997a).

Sharp changes in shell characteristics have been noted between populations located around the edge of one of the geographical areas (Lesser Kabylia). This is defined as a suture zone resulting from secondary contact between peripheral populations of the two regions (Guiller et al, 1996). Such abrupt changes have not been observed for genitalia measurements (see Figure 5(B)). However, populations from the Eastern and Western entities seem to have evolved independently for a sufficiently long time to produce contrasted evolutionary allometries involving shell size and genitalia measurements, sometimes with spectacular consequences. Thus, adult individuals from the eastern population of Hammam Meskoutine (A17), which have a conical shell with a size in the middle range of the species $(\mathrm{SD}=31.5 \pm 2.2 \mathrm{~mm})$ but which are of a small size compared with the other snails from Eastern Maghreb, are characterized by a fully developed genital apparatus, the proportions of which are comparable to those of juveniles from western European populations (Madec and Guiller, 1994). On the other hand, snails from the population of Djemila (A14), which can be considered as the most representative of the contact zone (see Guiller et al, 1996), also have a conical shell, but have genitalia of an intermediate size (eg, DIVL), which is about average for the species. Although genital evolution is beyond the scope of this study, such a pattern of covariation should have important mechanical implications leading to an eventual precopulatory isolation between snails from the eastern and western clusters. Detailed information is thus needed about (i) genetic exchanges between populations of the contact zone in relation to both mechanical constraints and the possibility of assortative matings, which have been observed in other Helicidae (Baur, 1998), and (ii) the process(es) responsible for the geographical differentiation of 'primary' sexual traits (see Arnqvist, 1997; Eberhard et al, 1998).

\section{Acknowledgements}

We thank J Brookfield and an anonymous reviewer for insightful comments and for checking the English on prior drafts of this manuscript. 


\section{References}

Arnqvist G (1997). The evolution of animal genitalia: distinguishing between hypotheses by single species studies. Biol J Linn Soc 60: 365-379.

Baur B (1998). Sperm competition in molluscs. In: Birkhead TR, Möller AP (eds) Sperm Competition and Sexual Selection, Academic Press: London. pp 255-306.

Bookstein FL (1989). 'Size and shape': a comment on semantics. Syst Zool 38: 173-180.

Bossart JL, Prowell DP (1998). Genetic estimates of population structure and gene flow: limitations, lessons and new directions. Trends Ecol Evol 13: 202-206.

Boulding EG, Hay TK (1993). Quantitative genetics of shell form of an intertidal snail: constraints on short-term response to selection. Evolution 47: 576-592.

Cadima JFCL, Jolliffe IT (1996). Size- and shape-related principal component analysis. Biometrics 52: 710-716.

Cain AJ (1981). Variation in shell shape and size of helicid snails in relation to other Pulmonates in faunas of the Palaeartic region. Malacologia 21: 149-176.

Cameron RAD, Cook LM (1989). Shell size and shape in Madeiran land snails: do niches remain unfilled? Biol J Linn Soc 36: 79-96.

Dupont-Nivet M, Guiller A, Bonnet JC (1997a). Genetic and environmental variability of adult size in some stocks of the edible snail Helix aspersa. J Zool 241: 757-765.

Dupont-Nivet M, Mallard J, Bonnet JC, Blanc JM (1997b). Quantitative genetics of growth traits in the edible snail Helix aspersa Müller. Genet Sel Evol 29: 571-587.

Eberhard WGB, Huber A, Rodriguez RF, Briceno RD, Salas I (1998). One size fits all? Relationships between the size and degree of variation in genitalia and other body parts in twenty species of insects and spiders. Evolution 52: 415-431.

Germain, L (1908). Etude sur les Mollusques recueillis par M. Henri Gadeau de Kerville pendant son voyage en Khroumirie (Tunisie). In: Gadeau de Kerville (ed) Voyage zoologique en Khroumirie, Baillière: Paris. pp. 129-206.

Gittenberger E (1996). Adaptations of the aperture in terrestrial Gastropod-Pulmonate shells. Neth J Zool 46: 191-205.

Giusti F, Manganelli G (1984). Relationships between geological land evolution and present distribution of terrestrial gastropods in the western mediterranean area. In: Solem A, Van Bruggen AC (eds) World-Wide Snails, E.J. Brill: Leiden. pp 70-92.

Goodfriend GA (1986). Variation in land snail shell form and size and its causes: a review. Syst Zool 35: 204-223.

Guiller A, Coutellec-Vreto MA, Madec L (1996). Genetic relationships among suspected contact zone populations of Helix aspersa (Gastropoda: Pulmonata) in Algeria. Heredity 77: 113-129.

Guiller A, Coutellec MA, Madec L, Deunff J (2001). Molecular support for evolutionary history of the land snail Helix aspersa in Western Mediterranean. Mol Ecol 10: 81-89.

Guiller A, Madec L, Daguzan J (1994). Geographical patterns of genetic differentiation in the landsnail Helix aspersa Müller (Gastropoda: Pulmonata). J Molluscan Stud 60: 205-221.

Johnston MR, Tobachnick RE, Bookstein FL (1991). Landmarkbased morphometrics of spiral accretionary growth. Paleobiology 17: 19-36.

Johnson MS, Black R (2000). Associations with habitat versus geographic cohesiveness: size and shape of Bembicium vittatum Philippi (Gastropoda: Littorinidae) in the Houtman Abrolhos Islands. Biol J Linn Soc 71: 563-580.

Jolicoeur D (1963). The multivariate generalization of the allometry equation. Biometrics 19: 497-499.

Koene JM, Chase R (1998). Changes in the reproductive system of the snail Helix aspersa caused by mucus from the love dart. J Exp Biol 201: 2313-2319.
Lace LA (1992). Variation in the genitalia of the land snail Heterostoma paupercula (Lowe, 1831) (Helicidae) in Madeira. Biol J Linn Soc 46: 115-129.

Lazaridou-dimitriadou M, Karakousis Y, Staikou A (1993). Geographic variation in shell morphology and isoenzymes of Helix aspersa Müller, 1774 (Gastropoda, Pulmonata), the edible land snail, from Greece and Cyprus. Heredity 71: 1-14.

Legendre P, Fortin MJ (1989). Spatial pattern and ecological analysis. Vegetatio 80: 107-138.

Madec L (1991a). Enzymatic variation in natural populations of Helix aspersa Müller. CR Acad Sci Paris 313(3): 339-344.

Madec L (1991b). Genetic divergence in natural populations of the landsnail Helix aspersa Müller, 1774. J Molluscan Stud 57: 483-487.

Madec L, Bellido A, Guiller A (1996). Statistical and biogeographical significances of patterns of morphological and biochemical variation in the land snail Helix aspersa. CR Acad Sci III Paris 319: 225-229.

Madec L, Daguzan J (1993). Geographic variation in reproductive traits of Helix aspersa Müller studied under laboratory conditions. Malacologia 35: 99-117.

Madec L, Desbuquois C, Coutellec-Vreto MA (2000). Phenotypic plasticity in reproductive traits: importance in the life history of the land snail Helix aspersa in a recently colonized habitat. Biol J Linn Soc 69: 25-39.

Madec L, Guiller A (1993). Observations on distal genitalia and mating activity in three conchologically distinct forms of the land snail Helix aspersa Müller. J Molluscan Stud 59: 455-460.

Madec L, Guiller A (1994). Geographic variation of distal genitalia in the landsnail Helix aspersa (Mollusca: Gastropoda). J Zool 233: 215-231.

Madec L, Guiller A, Coutellec-Vreto MA, Desbuquois C (1998). Size-fecundity relationships in the land snail Helix aspersa: preliminary results on a form outside the norm. Invert Reprod Dev 34: 83-90.

Mc Ghee Jr GR (1999). Theoretical Morphology: The Concept and its Applications. Columbia University Press: New York.

Monteiro LR, Bordin B, Furtado Reis S (2000). Shape distances, shape spaces and the comparison of morphometric methods. Trends Ecol Evol 15: 217-220.

Oden, NL (1984). Assessing the significance of a spatial correlogram. Geogr Anal 16: 1-16.

Parsons KE (1997). Contrasting patterns of heritable geographic variation in shell morphology and growth potential in the marine gastropod Bembicium vittatum: evidence form field experiments. Evolution 51: 784-796.

Raup DM (1966). Geometric analysis of shell coiling: general problems. J Paleontol 40: 1178-1190.

Rohlf FJ (1990). Morphometrics. Annu Rev Ecol Syst 21: 299-316.

Rohlf FJ, Marcus LF (1993). A revolution in morphometrics. Trends Ecol Evol 8: 129-132.

Samadi S, David P, Jarne P (2000). Variation of shell shape in the clonal snail Melanoides tuberculata, and its consequences for the interpretation of fossil series. Evolution 54: 492-502.

Sokal RR, Oden NL, Thomson BA (1997). A simulation study of microevolutionary inferences by spatial autocorrelation analysis. Biol J Linn Soc 60: 73-93.

Somers KM (1989). Allometry, isometry and shape in principal components analysis. Syst Zool 38: 169-173.

Stone JR (1996). Computer-simulated shell size and shape variation in the caribbean land snail genus Cerion: a test of geometrical constraints. Evolution 50: 341-347.

Stone JR (1998). Landmark-based thin-plate spline relative warp analysis of gastropod shells. Syst Biol 47: 254-263.

Stone JR (1999). Using a mathematical model to test the null hypothesis of optimal shell construction by four marine gastropods. Mar Biol 134: 397-403.

Taylor JW (1913). Monograph of the Land and Freshwater Mollusca of the British Isles. Taylor Brothers: Leeds. 
Thioulouse J, Chessel D, Dolédec S, Olivier JM (1997). ADE-4: a multivariate analysis and graphical display software. Statist Comput 7: 75-83.

Van Osselaer C, Tursch B (2000). Variability of the genital system of Helix pomatia L. 1758 and H. lucorum L. 1758 (Gastropoda: Stylommatophora). J Molluscan Stud 66: 499-515.

Ward JH (1963). Hierarchical grouping to optimize an objective function. J Am Statist Assoc. 58: 238-244.
Welter-Schultes FW (2000). The pattern of geographical and altitudinal variation in the land snail Albinaria idaea from Crete (Gastropoda: Clausiliidae). Biol J Linn Soc 71: 237-250.

Yoccoz N (1993). Morphométrie et analyses multidimensionnelles. Une revue des méthodes séparant taille et forme. In: Lebreton JD, Asselain B (eds) Biométrie et Environnement, Masson: Paris. pp 73-99. 